\title{
Hospital and patient factors influencing the health status among patients with schizophrenia, thirty days after hospital discharge: multi-level analysis
}

Anantree Smithnaraseth ${ }^{1}$, Acharaporn Seeherunwong ${ }^{2^{*}}$ (D, Rungnapa Panitrat ${ }^{3}$ and Mathuros Tipayamongkholgul ${ }^{4}$

\begin{abstract}
Background: The time between discharge from hospital and transition to community and home is a critical period for health status among patients with a mental illness, including patients with schizophrenia. This study aimed to investigate crucial patient factors (patient-level) and hospital factors (hospital-level) affecting health status and see whether patient factor effects on health status vary with hospital factors, 30 days after hospital discharge.

Methods: This is a prospective study of 1255 patients with schizophrenia and their primary caregivers from 13 public mental hospitals across Thailand. Logistic regression and multi-level logistic regression was used to investigate the effects of patient and hospital factors simultaneously on health status, 30 days after hospital discharge.

Results: The intraclass correlation coefficient indicated that $14 \%$ of the change in health status was explained by the differences between hospital. Poor health status was identified in $14.26 \%$ of patients, 30 days after hospital discharge. The majority of participant patients were male (69.8\%), single (71.87\%), and the average age was 38.09 $(\mathrm{SD}=9.74)$. The finding also showed that the patient factors; being female $\left(\mathrm{OR}_{\mathrm{adj}} .53,95 \% \mathrm{Cl} .31, .92\right)$, perceived moderate and high levels of positive aspect of caregiving $\left(\mathrm{OR}_{\mathrm{adj}} .24,95 \% \mathrm{Cl} .14, .42\right.$ and $\left.\mathrm{OR}_{\mathrm{adj}} .05,95 \% \mathrm{Cl} .02, .09\right)$, perceived readiness for hospital discharge $\left(\mathrm{OR}_{\mathrm{adj}} .21,95 \% \mathrm{Cl} .13,33\right)$, partial and full adherence to treatment $\left(\mathrm{OR}_{\mathrm{adj}}\right.$ $.24,95 \% \mathrm{Cl} .14,42$ and $\mathrm{OR}_{\mathrm{adj}} .31,95 \% \mathrm{Cl} .20,47$ ) showed a reduced likelihood of developing poor health status except substance use $\left(\mathrm{OR}_{\mathrm{adj}} 1.55,95 \% \mathrm{Cl} .98,2.44\right)$. Hospital factors; discharge planning process and nurse-patient ratio $\left(\mathrm{OR}_{\mathrm{adj}} 1.64,95 \% \mathrm{Cl} 1.17,2.30\right.$ and $\left.\mathrm{OR}_{\mathrm{adj}} 1.16,95 \% \mathrm{Cl} 1.09,1.22\right)$ showed an increased likelihood of developing poor health status, 30 days after hospital discharge.

Conclusions: Findings provide relevant information on how both patient and hospital factors determine health status. These results might lead to better targeting of mental health service policy and enable more precise information gathering and allocation of resources. However, future research should be more focused and continue investigating the pathways through which hospital factors influence health status post-discharge.
\end{abstract}

Keywords: Schizophrenia, Health status, Post-discharge, HoNOS, Multi-level logistic regression

\footnotetext{
* Correspondence: acharaporn.see@mahidol.edu

${ }^{2}$ Department of Mental Health and Psychiatric Nursing, Faculty of Nursing,

Mahidol University, 999 Phuttamonthon 4 Road, Salaya, Nakhon Pathom

73170, Thailand

Full list of author information is available at the end of the article
}

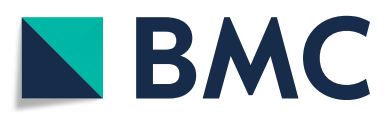

(- The Author(s). 2020 Open Access This article is licensed under a Creative Commons Attribution 4.0 International License, which permits use, sharing, adaptation, distribution and reproduction in any medium or format, as long as you give appropriate credit to the original author(s) and the source, provide a link to the Creative Commons licence, and indicate if changes were made. The images or other third party material in this article are included in the article's Creative Commons licence, unless indicated otherwise in a credit line to the material. If material is not included in the article's Creative Commons licence and your intended use is not permitted by statutory regulation or exceeds the permitted use, you will need to obtain permission directly from the copyright holder. To view a copy of this licence, visit http://creativecommons.org/licenses/by/4.0/. The Creative Commons Public Domain Dedication waiver (http://creativecommons.org/publicdomain/zero/1.0/) applies to the data made available in this article, unless otherwise stated in a credit line to the data. 


\section{Background}

Schizophrenia is a chronic mental disorder that frequently causes problems for the general health of individuals. It affects approximately $1-1.15 \%$ of the global population, which afflicts over 20 million individuals worldwide, primarily in young adulthood, and slightly more men than women [1-4]. Schizophrenia is characterized by impairment of insight, judgment, mood, and can produce psychotic symptoms such as hallucinations and delusions, impacting a patient's global functioning [5-7]. Also, schizophrenia has high social costs due to high treatment costs, loss of productivity, and considerable public assistance [8].

Since the deinstitutionalization policy movement, most patients with a mental illness, including patients with schizophrenia, are now being cared for in the community and at home. In theory, it appeared to be a logical and sound concept to improve the conditions and care of patients with a mental illness. However, when one or more of the individual reasons that supported deinstitutionalization turned out to be false, for either the patient or community, problems began to arise [9]. A key issue affecting patients' health outcomes is the lack of a smooth transition into integrated and collaborative care planning by the mental health and social care services and inpatient, outpatient, and community mental health care [10]. Research suggests that low transition out of inpatient psychiatric hospitals and inadequate discharge planning may have adverse effects on patients and their families [11]. Moreover, poor transition planning is associated with a higher degree of non-adherence to treatment, worsened prognosis, and increased risk of relapse or readmission [12-17].

When working with patients with a mental illness, mental health care teams, especially nurse staff, must provide direct care in terms of prevention and in promoting and focusing on the patient's health and potential during admission until discharge and post-discharge. There was a considerable gap in the quality of care offered since the number of professional health workers dealing with mental health in low and middle-income countries (LMICs) is grossly inadequate [18], including in Thailand. Almost half the world's population lives in countries where, on average, there is only one psychiatrist to serve 200,000 or more people [18]. The World Health Organization in 2015 reported that there were $43.5,15.2$, and 8.7 mental health professionals per 100, 000 of the population in samples of the EU, American, and the Western Pacific regions, respectively, and 4.8 per 100,000 of the people in South East Asia. Over 24 staff nurses worked in mental health in the EU, compared to 0.6 in Africa, and 2.6 per 100,000 of the population in South East Asia [19]. Hence, professional mental health staffing, especially nurse staffing, was a critical mental health care system concerned because of its association with quality of care, patient needs, and health outcomes. Even though a growing research interest by nurses, mental health nursing research is still limited, and the nurse to patient ratio effects on health outcomes after hospital discharge are rarely discussed.

Health status in this study refers to all aspects of health (behavioral, physical, clinical, and social) of people who use mental health services due to severe mental illness, including patients with schizophrenia. Monitoring the health status of patients with schizophrenia after hospital discharge may provide health care professionals the information to improve service delivery. Also, monitoring day-after hospital discharge health status for schizophrenia looks to the changes and variations in overall health status. Forward-looking surveillance needs further elucidation but maybe a way to establish or plan better treatment for these patients. The factors associated with health status among patients with schizophrenia after hospital discharge is understood according to the Andersen Healthcare Utilization Model (Andersen's Emerging Model phase 4, 1995). Andersen's model focuses on the health service systems where patient needs are met through professional caregiving. It is a multi-level model that incorporates personal and contextual or health service delivery determinants of health service use [20]. Personal or patient factors as predisposing characteristics among patients with schizophrenia that are often associated with health status were young age, male gender, low level of education [5, 2123], long duration of illness [24-26], and substance use $[27,28]$. The positive aspect of caregiving (PAC) from caregivers is an enabling resource that influences treatment adherence and improves health status among patients with schizophrenia $[29,30]$. Also, caregivers report lower rates of depression and burden related to daily care activities [31] and improvement in outcome due to long-term adherence to treatment by patients [32]. Finally, the severity of illness at discharge could be measured by readiness for hospital discharge (RHD), as perceived by the patients' need components. Patients who saw themselves as unready for release showed the highest impairment in health status, including impaired community functioning, more severe psychopathology, more impaired cognitive functioning, and more inadequate psychosocial adjustment [13, 33, 34].

Environment or hospital factors include the health care system and external environment, which refers to the amount and distribution of health service facilities or availability of service delivery that support the individual patient [35]. Previous studies have reported that adequate care provision during hospitalization by staff affects treatment adherence, self-care improvement, and 
cognitive and social functioning improvements among patients with schizophrenia [11]. Staff to patient ratio was the specific variable that substantially impacted the quality of care concerning the risk of readmission within 30-days and patient's health outcomes [36-38].

One problem posed by the disorder is the limited number of studies and the lack of investigations into the factors that influence the health status of patients with schizophrenia after hospital discharge. Most of the research has focused on patient factors, and less attention has been given to hospital factors, in particular, the discharge planning process, nurse staffing, and the health status of patients with schizophrenia. Thus, to provide a more comprehensive view and gain insight into the factors that influence health status after hospital discharge, it is necessary to explore how patient and hospital factors contribute to the health status of patients with schizophrenia in thirteen mental hospitals across Thailand. This study aimed to examine the patient factors (patient-level) and hospital factors (hospital-level) influencing health status among patients with schizophrenia 30 days after hospital discharge. Emphasis is placed on exploring the actual effect of these elements on health status, considering the impact of their levels. We hypothesize that patient and hospital factors affect health status among these patients, 30 days after hospital discharge.

\section{Methods}

\section{Setting}

Thailand is a country in South East Asia, with a population of approximately 63 million persons. It has five regions (central, northern, northeastern, eastern, and southern) and seventeen public mental hospitals distributed throughout the country. These hospitals provide 13.8 beds per 100,000 population with thirteen public mental hospitals for adults and four for children and adolescents. All public mental hospitals are organizationally integrated with outpatient facilities [39]. The Mental Health Department (MHD) is a representative of the Ministry of Public Health (MOPH) and is responsible for the implementation and administration of mental health services and issues mental health regulations and notifications for the execution of service delivery. After the health reform in 2012, the role of MHD now includes the development of mental health policy and mental health service regulations at provincial and district levels [40]. This study focuses on 20-59-year-old adult patients with schizophrenia from thirteen public mental hospitals invited to participate in the study. Based on this large population, the appropriate method of participant sampling from different settings used a proportion-to-size sampling method.

\section{Study participants}

The inclusion criteria for the participant patients included: 1) being 20 to 59 years of age; 2) principal or first diagnosis of either schizophrenia (F20.0-F20.9) or schizoaffective disorders (F25.0, F25.1, F25.2, F25.8, F25.9) based on ICD-10; 3) were inpatients of public mental hospitals and whom their psychiatrist had permitted discharge from the hospital to return home during March 2018 to June 2019; 4) living with a close family member or caregiver; 5) able to understand and communicate in Thai, and 6) willing to participate in the study. Cases that were transferred to another inpatient facility due to physical problems were excluded. The primary participant caregivers who had been most involved with participant patients in the last 3 months, living with the patient at home, able to understand and communicate in Thai, were invited to participate in the study as well.

The number of patients with schizophrenia who were discharged from public mental hospitals in Thailand in 2015 was about 37,938 [41]. The Krejcie \& Morgan [42] method was used to determine the required sample size. Based on previous evidence, we assumed a $40 \%$ dropout rate due to uncompleted questionnaires and the inability to contact patients after hospital discharge. The total required sample size was calculated to be 1500 participating patients and their primary caregivers starting on the day of hospital discharge from thirteen mental hospitals within the period of the study. In the current study, we excluded participants due to questionnaires with missing data $(n=54)$, inconvenience, and inability to contact location phone numbers for the telephone interview 30 days after hospital discharge $(n=191)$, ending up with a sample of 1255 participants and yielding a response rate of $83.66 \%$.

\section{Measures}

Health status was assessed using The Health of the Nation Outcome Scale (HoNOS), developed by the Royal College of Psychiatrists' Research Unit (CRU) in 1996 and translated into the Thai language by Phuaphanprasert et al. [43]. The HoNOS consists of 12-items, including symptoms, functioning, social relationships, and environmental issues. Each item was rated on a scale of 0 to 4 with 0 meaning no problem, 1 meaning a problem not requiring any intervention, and 2,3 , and 4 corresponded to a "mild," "moderate," or "severe" problem, respectively. The total HoNOS is categorized through two cut-off points: $0=$ improved clinical (good) health status (0-12) and $1=$ worsening (poor) health status (more than 12) [44]. Cronbach's alpha obtained for the pilot group and total participating patients in the current study was .90. The HoNOS was assessed for participant 
patients on the day of hospital discharge and 30 days later.

\section{Patient factors (patient-level)}

The following factors were included in descriptive statistics: gender (male or female), age-group (20-32 yrs., 33$45 \mathrm{yrs}$. and $46-59$ yrs.), educational level (no education, elementary, secondary, vocational, or higher education level), duration of illness (measured in the number of years), substance use (measured dichotomously as no $=0$ and yes $=1$ ). These were applied to the participant patients on the day of hospital discharge, except for treatment adherence (not adhering to treatment, partially adhering to treatment, and fully-adhering to treatment), assessed thirty days later.

Readiness for hospital discharge (RHD) of the patients was assessed using the Readiness for Hospital Discharge Scale (RHDS), developed by Wiess et al. [45] and translated into the Thai language by Sriprasong et al. [46]. The RHDS consists of 23-items and four subscales, including personal status, knowledge, coping ability, and expected support. Each item was rated on a scale of 0 to $10(0=$ not ready to $10=$ ready to discharge $)$ with higher ratings indicating greater perceived readiness for discharge. Cronbach's alpha of total scale findings was .93 and .88 from a pilot study and all participants in the current study. The RHDS was administered to participant patients on the day of hospital discharge.

The positive aspects of caregiving by caregivers were assessed using the Positive Aspect of Caregiving (PAC), developed by Tarlow et al. [47]. The PAC consists of 11items, phrased as statements about the caregiver's mental and affective state as part of the caregiving experience. Each item was rated on a 5-point ordinal scale, ranging from 1 (strongly disagree) through 5 (strongly agree). We applied the translation processes of forwardtranslation and then back-translation specified in the WHO guidelines for the PAC. The aggregated values ranged from 11 to 55, divided into three PAC groups (low score 1-25, moderate score 26-40, and high score 41-55). Cronbach's alpha of the total scale findings was $.90-.96$ from a pilot study and all the participants in the current study. The PAC was administered to the participating caregivers when the participating patients were discharged from the hospital.

\section{Hospital factors (hospital-level)}

Data were obtained from the annual report of the MHD and administration nurse reports from thirteen mental hospitals. They included: 1) a hospital profile regarding the number of beds, the number of professional mental health staff (psychiatrists, nurses, psychologists, and social workers) working in each hospital, and the number of patient hospitalizations during the period of the study [48]; 2) discharge planning process is the process of the development of an individualized discharge plan for a patient before leaving the hospital for the home to reduce unplanned readmission to the hospital [49]. Discharge planning can be an individualized intervention or group-based intervention. In this study, the intervention was classified in one of two ways: as an individual and group intervention by a nurse and a group intervention only by mental health care teams. Data were obtained from medical records. The total number of nurses at each unit was collected from administration nurse reports and recorded by the RA working at each setting. Nurse staffing was calculated as the total number of nurses on the day, evening, and night shifts of the unit from each hospital divided by the number of patients who stay in that unit. The average number of nurses and patients was aggregated in the hospital factors as a nurse to patient ratio.

\section{Data collection}

After the approval of the Mahidol University Institutional Review Board, Nursing (COA No.IRB-NS2018/ 434.0103) and the Mental Health Department Institutional Review Board (DMH-IRB.COA009/2561) for permission to collect the data from thirteen public mental hospitals, under the Ministry of Public Health Administration in Thailand, data collection commenced as 1) The researcher selected the research assistants (RA) who working as nurses in each hospital, then made an appointment to describe the research objectives, research procedures, criteria of samples, instruments and data collection process including human rights protections; 2) the RA attended and observed the researcher collecting data and any misunderstandings about data collection procedures were discussed and reviewed; 3) the RA practiced collecting data at hospitals where they worked while the researcher also observed until they were able to collect data independently.

For participating patients with schizophrenia, the following process was followed: 1) The researcher or RA coordinated the heads or senior nurses of each participating ward to collected data of participating patients on the day of hospital discharge; 2) invited participating patients to a private area, gave them information about the study and the confidentiality of the data, had them sign an informed consent document, and provided them questionnaires to measure patient characteristics, RHD and health status at baseline; 3 ) after data collection, the second interview date and time was scheduled. Thirty days later, as expected, the participating patients were called to complete the telephone interview to measure their current health status and treatment adherence.

The process for primary caregivers included: 1) The researcher or RA entrusted the heads or senior nurses of 
each participating ward with the task of collecting data from the participating caregiver in the ward on the day that participating patients were to be discharged; 2) invited participating caregivers to a private area, gave them the information they required about the study, had them sign an informed consent document, and provided a questionnaire to measure PAC. Finally, the researcher or RA gave a small gift to both participating patients and their caregivers for participation. Each questionnaire was given a code number for identification purposes and to assure confidentiality.

\section{Statistical analysis}

Descriptive statistics were used to examine the distribution of participating patients with schizophrenia for demographic and mental hospital characteristics. Logistic regression analysis was used to determine patient and hospital factors on health status and enter the base model of multi-level logistic regression analysis. Multilevel logistic regression analysis is followed with all the significant elements found in the previous univariate analysis to assess their simultaneous effect on the health status. There are three steps: first, we estimated a null model and calculated the intraclass-correlation coefficient (ICC) (Model 1). Secondly, we included patient factors (Model 2) and, finally, had both patient and hospital factors in addition to hospital-specific random effects (Model 3). At each step, Akaike's Information Criterion (AIC) was calculated, and the model with the lowest AIC value chosen as the final model that Hosmer \& Lemeshow showed as an acceptable model fit. The level of significance of the results was $p$-value $<0.05$. All analyses used the program STATA/IC version 16.1.

\section{Results}

\section{Descriptions of the demographic characteristics related to} health status

Table 1 details the demographic characteristics of a total of $N=1255$ patients with schizophrenia relative to their health status, at baseline and 30 days after discharge from thirteen mental health hospitals. Of all patients, 5.02 and $14.26 \%$ had poor health status at baseline and 30 days after release, respectively. The health status at baseline showed an average HoNOS score of 3.81 and 6.47 at 30 days after discharge among participant patients. On average, the total HoNOS increased by 2.66 from the baseline, indicating worsening or poor health status. Also, the health status varied with demographic characteristics; for example, males were more likely to have poor health status than females. Having poor health status was more frequently reported in the younger age groups, single status, uneducated/ elementary and secondary/vocational, and unemployed, than among older, married status, and those having a higher educational level and employment. Poor health status was also more prevalent among those who frequently or ever used drugs or alcohol. Even those who claimed they were ready for hospital discharge acknowledged that they had poor health status after hospital discharge. Moreover, it was confirmed by the findings that the participant patients who did not adhere to treatment, although graded mild or moderate of PAC from their caregivers, were likely to poor health status after hospital discharge.

Information regarding the thirteen mental hospital characteristics is shown in Table 2, as presented in the Supplementary Material. The number of beds varied from area to area in Thailand, with the northeast region having smaller hospitals (90 beds) while the central region had larger hospitals (500-750 beds). More than half of the mental hospitals $(n=8)$ provided discharge planning processes that focused on either individual discharge or group discharge by nurses, and administration of service delivery as acute care units (acutely ill patient care until hospital discharge) (61.53\%). The central region had the most professional mental health staff (PMHS) (33.21\%), followed by the northeast (30.29\%), while the eastern region had fewer PMHS than any other part of Thailand $(2.83 \%)$. The average nurse-patient ratio on the day shift was 8.41 (SD 2.34).

\section{Patient and hospital factors influencing health status among patients with schizophrenia, thirty days after hospital discharge}

The patient factors influencing health status when the participating patients were female $\left(\mathrm{OR}_{\mathrm{adj}} .53,95 \% \mathrm{CI} .31\right.$, .92), moderate and high level of PAC from primary caregivers $\left(\mathrm{OR}_{\mathrm{adj}} .24,95 \% \mathrm{CI} .14, .42\right.$ and $\mathrm{OR}_{\mathrm{adj}} .05,95 \% \mathrm{CI}$ $.02, .09)$, perceived $\mathrm{RHD}\left(\mathrm{OR}_{\mathrm{adj}} .21\right.$, 95\%CI .13,.33), partial and full adherence to treatment $\left(\mathrm{OR}_{\mathrm{adj}} .24\right.$, 95\% CI .14,.42 and $\mathrm{OR}_{\mathrm{adj}} .31,95 \% \mathrm{CI} .20, .47$ ) showed reduced opportunity of developing poor health status at statistical significance except for substance use $\left(\mathrm{OR}_{\mathrm{adj}}\right.$ $1.55,95 \% \mathrm{CI} .98,2.44)$. For hospital factors, the discharge planning process based upon group intervention by teams and the nurse-patient ratio showed an increased opportunity for developing poor health status at statistical significance $\left(\mathrm{OR}_{\mathrm{adj}} 1.64,95 \% \mathrm{CI} 1.17,2.30\right.$, and $\mathrm{OR}_{\text {adj }} 1.16,95 \% \mathrm{CI} 1.09,1.22$ ) (Table 3).

The ROC curve for the predictive variables associated with the health status among the participating patients is presented in Fig. 1. Under the null hypothesis (straight diagonal line), the area under the curve is 0.5 ; the two factors improved the area under the curve to 0.8823 . This improvement indicated that the model provides better predictive accuracy than obtained by chance. 
Table 1 Demographic characteristics of patient with schizophrenia based on health status, at baseline and thirty days after hospital discharge

\begin{tabular}{|c|c|c|c|c|c|}
\hline \multirow[t]{2}{*}{ Variables } & \multirow[t]{2}{*}{$\mathbf{N}(\%)$} & \multicolumn{2}{|c|}{$\begin{array}{l}\text { Health Status } \\
\text { at Baseline }\end{array}$} & \multicolumn{2}{|c|}{$\begin{array}{c}\text { Health Status } \\
\text { at 30-days after hospital } \\
\text { discharge }\end{array}$} \\
\hline & & $\begin{array}{l}\text { Good } \\
\text { n (\%) }\end{array}$ & $\begin{array}{c}\text { Poor } \\
\text { n (\%) }\end{array}$ & $\begin{array}{l}\text { Good } \\
\text { n (\%) }\end{array}$ & $\begin{array}{c}\text { Poor } \\
\text { n (\%) }\end{array}$ \\
\hline Total & 1255 & $1,192(94.98)$ & $63(5.02)$ & 1076(85.74) & $179(14.26)$ \\
\hline \multicolumn{6}{|l|}{ Gender } \\
\hline - male & & $822(93.84)$ & $54(6.17)$ & $729(83.22)$ & $147(16.78)$ \\
\hline - female & & $370(97.63)$ & $9(2.37)$ & $347(91.56)$ & $32(8.44)$ \\
\hline \multicolumn{6}{|l|}{ Age (yrs.) } \\
\hline$-20-32$ & & $366(93.60)$ & $25(6.40)$ & $329(84.14)$ & $62(15.86)$ \\
\hline$-33-45$ & & $539(95.23)$ & $27(4.77)$ & $486(85.87)$ & $80(14.13)$ \\
\hline - more than 46 & & $287(96.30)$ & $11(3.70)$ & $261(87.58)$ & $37(12.42)$ \\
\hline \multicolumn{6}{|c|}{ (average age 38.09 yrs., SD 9.74, $\min 20$ yrs., $\max 59$ yrs.) } \\
\hline \multicolumn{6}{|c|}{ Marital status } \\
\hline - single & & $849(94.12)$ & $53(5.88)$ & $751(83.26)$ & $151(16.74)$ \\
\hline - married & & 183(97.86) & $4(2.14)$ & $178(95.19)$ & $9(4.81)$ \\
\hline - separate/divorced/widowed & & $160(96.39)$ & $6(3.61)$ & $147(88.55)$ & $19(11.45)$ \\
\hline \multicolumn{6}{|l|}{ Educational level } \\
\hline - uneducated and elementary & & $467(94.16)$ & $29(5.85)$ & $427(86.10)$ & $69(13.90)$ \\
\hline - secondary and vocational & & $639(94.95)$ & $34(5.05)$ & $567(84.25)$ & $106(15.75)$ \\
\hline - higher educational & & $86(1)$ & $0(0)$ & $82(95.35)$ & $4(4.65)$ \\
\hline \multicolumn{6}{|l|}{ Family incomes } \\
\hline - less than 5000 THB & & $318(93.53)$ & $22(6.47)$ & $274(80.59)$ & $66(19.41)$ \\
\hline - 5001-10000 ТНВ & & $550(95.98)$ & $23(4.02)$ & $502(87.61)$ & $71(12.39)$ \\
\hline - 10001-20000 ТНВ & & $248(95.75)$ & $11(4.25)$ & $230(88.80)$ & $29(11.20)$ \\
\hline - more than 20000 THB & & $76(91.56)$ & $7(8.44)$ & $70(84.34)$ & $13(15.66)$ \\
\hline \multicolumn{6}{|l|}{ Employment status } \\
\hline - employed & & $738(95.48)$ & $35(4.52)$ & 684(88.49) & $89(11.51)$ \\
\hline - unemployed & & $454(94.19)$ & $28(5.81)$ & $392(81.33)$ & $90(18.67)$ \\
\hline \multicolumn{6}{|l|}{ Substance used } \\
\hline - yes & & $611(92.16)$ & $52(7.84)$ & $537(80.99)$ & $126(19)$ \\
\hline- no & & $581(98.15)$ & $11(1.85)$ & $539(91.05)$ & $53(8.95)$ \\
\hline \multicolumn{6}{|c|}{ Readiness for hospital discharge (RHD) } \\
\hline - yes & & $940(90.04)$ & 104(9.96) & & \\
\hline - no & & $136(64.45)$ & $75(35.55)$ & & \\
\hline \multicolumn{6}{|l|}{ Treatment adherence } \\
\hline - Non-adherence to treatment & & & & $587(77.75)$ & $168(22.25)$ \\
\hline - Partial-adherence to treatment & & & & $317(96.94)$ & $10(3.06)$ \\
\hline - Fully-adherence to treatment & & & & $172(99.42)$ & $1(0.58)$ \\
\hline \multicolumn{6}{|l|}{ Positive aspect of caregiving (PAC) } \\
\hline - Mild & & & & $35(38.04)$ & $57(61.96)$ \\
\hline - Moderate & & & & $281(76.36)$ & $87(23.64)$ \\
\hline - High & & & & $760(95.60)$ & $35(4.40)$ \\
\hline \multicolumn{6}{|c|}{ Average health status (HoNOS) (range); $3.81(0-33)$ at baseline and $6.47(0-48)$ 30-days after discharge } \\
\hline $\begin{array}{l}\text { THB=Thai Baht; HoNos }=\text { Health of the } \\
\text { For patients: demographic characterist } \\
\text { hospital. After that, treatment adherence } \\
\text { For caregivers: PAC was assessed on th }\end{array}$ & $\begin{array}{l}\text { Outcome } \\
\text { and bas }\end{array}$ & $\begin{array}{l}\text { ale } \\
\text { ne HoNOS were } \\
\text { follow-up HoNO } \\
\text { s discharged from }\end{array}$ & essed on th & $\begin{array}{l}\text { y of dischar } \\
\text { ays after disc }\end{array}$ & from the \\
\hline
\end{tabular}


Table 2 Mental hospital characteristics

\begin{tabular}{|c|c|c|c|c|c|c|}
\hline Characteristics & $\begin{array}{l}\text { Total } \\
\mathrm{n}(\%)\end{array}$ & $\begin{array}{l}\text { Central } \\
\mathrm{n}(\%)\end{array}$ & $\begin{array}{l}\text { North } \\
\mathrm{n}(\%)\end{array}$ & $\begin{array}{l}\text { Northeast } \\
\mathrm{n}(\%)\end{array}$ & $\begin{array}{l}\text { East } \\
\mathrm{n}(\%)\end{array}$ & $\begin{array}{l}\text { South } \\
\mathrm{n}(\%)\end{array}$ \\
\hline $\mathrm{N}$ of hospitals $(\mathrm{N}=13)$ & $13(100)$ & $3(23.10)$ & $2(15.38)$ & $5(38.46)$ & $1(7.70)$ & $2(15.38)$ \\
\hline \multicolumn{7}{|l|}{ Number of beds $(\mathrm{N}=13)$} \\
\hline - 90-250 beds & $6(46.15)$ & $1(33.33)$ & $1(50)$ & $2(40)$ & $1(100)$ & $1(50)$ \\
\hline - 251-499 beds & $5(38.46)$ & - & $1(50)$ & $3(60)$ & - & $1(50)$ \\
\hline$-500-750$ beds & $2(15.39)$ & $2(66.64)$ & - & - & - & - \\
\hline \multicolumn{7}{|l|}{ Discharge planning process $(\mathrm{N}=13)$} \\
\hline $\begin{array}{l}\text { - individual and group } \\
\text { intervention by nurse }\end{array}$ & $8(61.53)$ & $1(33.33)$ & $1(50)$ & $4(80)$ & $1(100)$ & $1(50)$ \\
\hline - group intervention by teams & $5(38.47)$ & $2(66.64)$ & $1(50)$ & $1(20)$ & - & $1(50)$ \\
\hline \multicolumn{7}{|l|}{$\begin{array}{l}\text { Administration of service delivery } \\
(\mathrm{N}=13)\end{array}$} \\
\hline - acute care unit & $8(61.53)$ & $2(66.64)$ & $2(100)$ & $2(40)$ & $1(100)$ & $1(50)$ \\
\hline - step down care unit & $5(38.47)$ & $1(33.33)$ & - & $3(60)$ & - & $1(50)$ \\
\hline $\begin{array}{l}\text { Number of professional mental } \\
\text { health staffs (PMHS) }(\mathrm{N}=1981)\end{array}$ & 1981(100) & $658(33.21)$ & $273(13.78)$ & $600(30.29)$ & $56(2.83)$ & 394(19.89) \\
\hline - psychiatrists & $127(6.41)$ & $57(8.66)$ & $20(7.32)$ & $33(5.50)$ & $3(5.36)$ & $14(3.55)$ \\
\hline - nurses & $1685(85.06)$ & $549(83.44)$ & $229(83.90)$ & $510(85)$ & $43(76.78)$ & $354(89.85)$ \\
\hline - psychologists & $82(4.14)$ & $23(3.50)$ & 13(4.76) & $28(4.66)$ & $5(8.93)$ & $13(3.30)$ \\
\hline - social workers & $87(4.40)$ & $29(4.40)$ & $11(4.02)$ & $29(4.84)$ & $5(8.93)$ & $13(3.30)$ \\
\hline \multicolumn{7}{|l|}{$\begin{array}{l}\text { Nurse staffing } \\
\text { (average nurse-patient ratio ir } \\
\text { - nurse-patient in day shift }\end{array}$} \\
\hline$\leq 1: 8$ & $8(61.53)$ & $3(37.50)$ & $2(25)$ & $1(12.50)$ & - & $2(25)$ \\
\hline$>1: 8$ & $5(38.47)$ & - & - & $4(80)$ & $1(20)$ & - \\
\hline \multicolumn{7}{|l|}{ - nurse-patient in evening shift } \\
\hline$\leq 1: 13$ & $4(30.77)$ & $2(50)$ & $2(50)$ & - & - & - \\
\hline$>1: 13$ & $9(69.23)$ & $1(11.11)$ & - & $5(55.56)$ & $1(11.11)$ & $2(22.22)$ \\
\hline \multicolumn{7}{|l|}{ - nurse-patient in night shift } \\
\hline$\leq 1: 13$ & $4(30.77)$ & $2(50)$ & $2(50)$ & - & - & - \\
\hline$>1: 13$ & $9(69.23)$ & $1(11.11)$ & - & $5(55.56)$ & $1(11.11)$ & $2(22.22)$ \\
\hline
\end{tabular}

Multi-level model influencing the health status among patients with schizophrenia, thirty days after hospital discharge

The final results of the multi-level model are presented in Table 4. The method used by Austin \& Merlo was based upon a three-step multi-level logistic regression model [50]. The ICC calculated from Model 1 is 0.14 $(p<0.001)$, which indicates that $14 \%$ of the change in health status is explained by the differences between mental hospitals or settings. The remaining $86 \%$ of the variance resided within hospitals. Model 2 includes patient factors that reveal a statistically significant correlation with health status in the logistic regression model (gender, substance use, PAC, RHD, and treatment adherence). The regression coefficients for all of the patient factors are all significant except for substance use. In the final model, Model 3, hospital factors were included and selected after validating other models because this simple model presented the quality of the fixed-effect model with the lowest values of AIC (Akaike information criteria) and Log-likelihood (LL) than as compared to other models. The results of the best model
(Model 3) show that patient levels do have an effect on the health status and do vary by hospital level. Female participant patients decrease the odds of poor health status by .75 points $(p<0.05)$, using males as the reference. Also, when the score of PAC from primary caregiver increased by one unit, the poor health status among patients with schizophrenia was reduced by 1.33 and 3.11 points $(p<0.001)$. When the participant patients were ready for hospital discharge, poor health status was reduced by 1.09 points $(p<0.001)$. The poor health status among participant patients with partial or full adherence to treatment was decreased by $1.67(p<0.001)$ and $2.84(p<0.05)$. Moreover, poor health status among participating patients increased by 0.11 points when the average ratio of nurse to patient increased $(p<0.05)$.

\section{Discussion}

This study investigates the patient and hospital factors influencing health status among patients with schizophrenia, 30 days after hospital discharge. Of the 1255 patients with schizophrenia, $14.26 \%$ had worsening or poor health status, 30 days after hospital discharge. 
Table 3 Logistic regression analysis of patient and hospital factors influencing health status, thirty days after hospital discharge

\begin{tabular}{|c|c|c|c|c|c|c|}
\hline Factors & $\mathrm{OR}_{\mathrm{adj}}$ & $\mathrm{SE}$ & $\mathrm{z}$ & \multicolumn{2}{|c|}{$95 \% \mathrm{CI}$} & p-value \\
\hline \multicolumn{7}{|l|}{ Patient factors (Patient-level) } \\
\hline \multicolumn{7}{|l|}{$\overline{\text { Gender }}$} \\
\hline - Male & Reference & & & & & \\
\hline - Female & .53 & .14 & -2.25 & .31 & .92 & 0.025 \\
\hline \multicolumn{7}{|l|}{ Age (yrs.) } \\
\hline$-20-32$ & Reference & & & & & \\
\hline$-33-45$ & .86 & .20 & -0.62 & .55 & 1.36 & 0.533 \\
\hline - more than 46 & .92 & .29 & -0.24 & .48 & 1.74 & 0.807 \\
\hline \multicolumn{7}{|l|}{ Educational level } \\
\hline - uneducated or elementary & Reference & & & & & \\
\hline - secondary or vocational & 1.10 & .22 & 0.50 & .73 & 1.66 & 0.614 \\
\hline - higher education & .50 & .28 & -1.19 & .16 & 1.55 & 0.232 \\
\hline Duration of illness (yrs.) & .99 & .01 & -0.07 & .96 & 1.03 & 0.941 \\
\hline \multicolumn{7}{|l|}{ Substance used } \\
\hline- no & Reference & & & & & \\
\hline - yes & 1.55 & .35 & 1.91 & .98 & 2.44 & 0.056 \\
\hline \multicolumn{7}{|l|}{ Positive aspect of caregiving (PAC) } \\
\hline - low & Reference & & & & & \\
\hline - moderate & .24 & .06 & -5.01 & .14 & .42 & $<0.001$ \\
\hline - high & .05 & .01 & -9.63 & .02 & .09 & $<0.001$ \\
\hline Ready for hospital discharge (RHD) & .31 & .06 & -5.43 & .20 & .47 & $<0.001$ \\
\hline \multicolumn{7}{|l|}{ Treatment adherence } \\
\hline - Non-adherence to treatment & Reference & & & & & \\
\hline - Partial-adherence to treatment & .19 & .06 & -4.71 & .09 & .38 & $<0.001$ \\
\hline - Fully-adherence to treatment & .05 & .05 & -2.84 & .00 & .40 & 0.004 \\
\hline _cons & 6.83 & 3.87 & 3.39 & 2.25 & 20.74 & 0.001 \\
\hline \multicolumn{7}{|l|}{ Hospital factors (Hospital-level) } \\
\hline $\begin{array}{l}\text { Discharge planning process } \\
\text { - individual and group } \\
\text { intervention by nurse }\end{array}$ & Reference & & & & & \\
\hline - group intervention by teams & 1.64 & .28 & 2.92 & 1.17 & 2.30 & 0.004 \\
\hline Nurse-patient ratio & 1.16 & .03 & 5.28 & 1.09 & 1.22 & $<0.001$ \\
\hline _cons & .03 & .01 & -11.03 & .02 & .06 & 0.000 \\
\hline
\end{tabular}

These findings go hand in hand with results in previous studies in other countries [51-54]. Nevertheless, the reasons for the higher chance of developing poor health status are not clear, but, generally, differences in prevalence are related to study factors, periods of measurement, operational definitions, and measurement use, as well as the targeted populations.

Our findings revealed five patient factors (gender-difference, substance use, PAC from primary caregivers, perceived RHD, and treatment adherence) significantly influenced the health status among patients with schizophrenia, 30 days after hospital discharge. For genderdifference, the female gender was a significant predictor of health status. This finding is consistent with previous studies in which women with schizophrenia achieved better health status or health conditions than men $[2,5$, 24, 55-57]. Therefore, the mental health service system should be sensitive to differences in gender to meet patients' specific needs and potentially improve outcomes. Moreover, substance use was also a significant predictor of health status. Previous studies have reported that past use of psychoactive drugs by patients with mental illness are a factor in treatment adherence and eventual health status. It is associated with the deterioration of health status, the risk for future non-adherence to treatment, relapse, and re-hospitalization [27, 28], and 


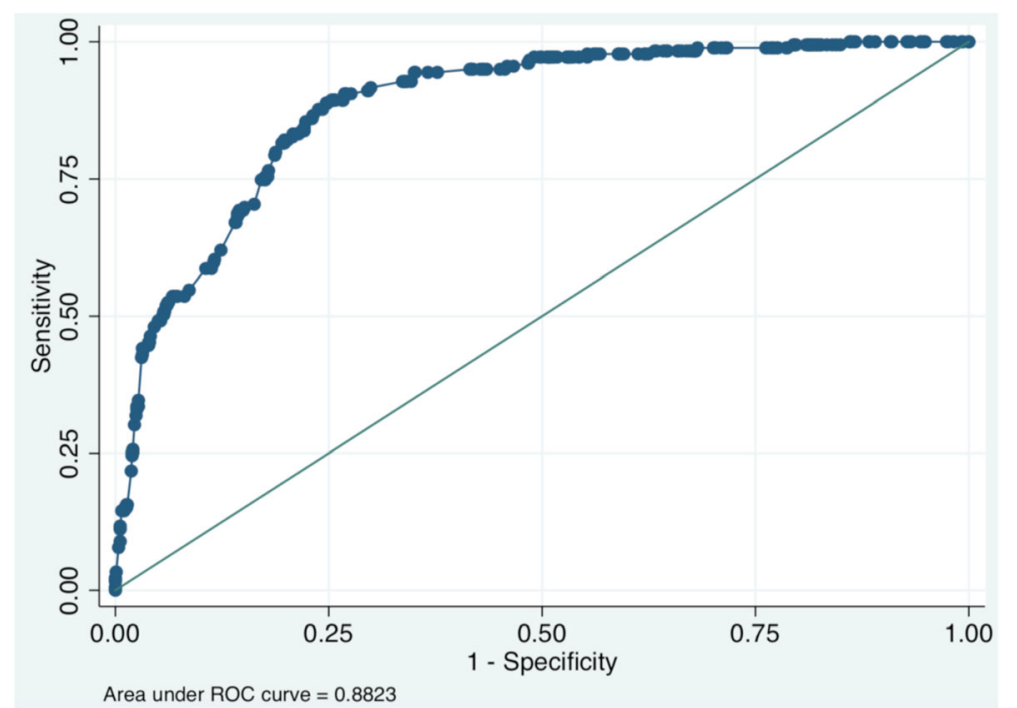

Fig. 1 The ROC curve for predictive variables associated with the health status among patients with schizophrenia, thirty days after hospital discharge

this study supports those findings. These findings might result from the mechanism or interactions between substance or alcohol use and intake of psychotropic medications on pharmacokinetics or pharmacodynamics, which can lead to adverse consequences. PAC from primary caregivers was also a significant predictor that influenced health status among participant patients. When caregivers had positive views and demonstrated positive aspects of caregiving, they had lower rates of depression and reduced upset related to care behaviors of patients. This behavior resulted in a lighter caregiver workload of daily care activities, improved outcomes from long-term adherence to treatment, and an overall improvement in the health status of patients [31, 32, 58]. Thus, the benefits of caregiver positive support underline the importance of the family system and community as a source of bonding, belonging, and aid in this environment [59]. The study also found that the participating patients who claimed they were ready for hospital discharge manifested similar health status effects as in previous studies [60-62]. However, the association between the readiness for hospital discharge and health status post-discharge remains unclear in individuals with schizophrenia. This lack of clarity is because most clinical trial literature focuses on symptoms, functional measures, and judgment about possible discharge made by health care providers. As expected, our findings showed non-adherence to treatment was influencing the health status among patients with schizophrenia in accord with past literature [63-67]. This finding sheds light on participants that adhere to treatment and present good health status after hospital discharge.
The findings of this study also identified two hospital factors (the discharge planning process and nurse staffing-patient ratio) that significantly influenced the health status among patients with schizophrenia after discharge from the hospital to their home. Since psychiatric nurses have close relations with patients throughout the treatment plan and the discharge planning process, they can play a crucial role in dealing with patients to improve treatment adherence, health status, and post-discharge outcome. However, there has been an inequitable distribution of PMHS in Thailand, which exists in several other countries. This maldistribution inevitably affects patients' health outcomes [68-71]. Our study findings amplify the findings of previous studies by showing the effectiveness of adequate nurse staffing, not only regarding care on the unit but after hospital discharge. A possible lesson from these findings is that it is vital to have an adequate ratio of providers to patients in psychiatric units, enabling nurses to devote more time to therapeutic interaction with the patients. They can look forward to applying more effective activity therapy such as psychoeducation or psychotherapy, for improving relationships with the patients. Patients with a mental illness, including patients with schizophrenia, having favorable views of and useful insights into their ailment during admission, has been shown to encourage better treatment adherence and punctual attendance at appointments. This attitude contributes to an improved health status after hospital discharge and a low risk of readmission [13, 27, 59]. Although there is a growing interest in mental health nursing research, there is still a limited evidence base. There is a lack of information 
Table 4 Estimated regression coefficients, odd ratio and variance components for the multilevel logistic regression models.

\begin{tabular}{|c|c|c|c|c|c|}
\hline \multirow[t]{2}{*}{ Factors } & \multirow[t]{2}{*}{ Model 1} & \multicolumn{2}{|c|}{ Model 2} & \multicolumn{2}{|c|}{ Model 3} \\
\hline & & $\begin{array}{l}\text { Regression } \\
\text { coefficient } \\
(95 \% \mathrm{CI})\end{array}$ & $\begin{array}{c}\mathrm{OR}_{\mathrm{adj}} \\
(95 \% \mathrm{CI})\end{array}$ & $\begin{array}{l}\text { Regression } \\
\text { coefficient } \\
(95 \% \mathrm{CI})\end{array}$ & $\begin{array}{c}\mathrm{OR}_{\mathrm{adj}} \\
(95 \% \mathrm{CI})\end{array}$ \\
\hline \multicolumn{6}{|c|}{ Patient factors (Patient-level) } \\
\hline Intercept & $\begin{array}{c}-1.91 * * * \\
(-2.35,-1.46)\end{array}$ & $\begin{array}{c}2.09 * * * \\
(.95,3.24)\end{array}$ & $\begin{array}{c}8.15^{* * *} \\
(2.59,25.65)\end{array}$ & $\begin{array}{c}1.26 \\
(-.32,2.86)\end{array}$ & $\begin{array}{c}3.54 \\
(.72,17.48)\end{array}$ \\
\hline Female & & $\begin{array}{c}-.78 * * \\
(-1.34,-.21)\end{array}$ & $\begin{array}{c}.45^{* *} \\
(.26, .80)\end{array}$ & $\begin{array}{c}-.75 * * \\
(-1.31,-.18)\end{array}$ & $\begin{array}{c}.47^{* *} \\
(.26, .82)\end{array}$ \\
\hline Substance used & & $\begin{array}{c}.30 \\
(-.15, .77)\end{array}$ & $\begin{array}{c}1.36 \\
(.85,2.17)\end{array}$ & $\begin{array}{c}.31 \\
(-.14, .78)\end{array}$ & $\begin{array}{c}1.37 \\
(.86,2.19)\end{array}$ \\
\hline Moderate PAC & & $\begin{array}{l}-1.31 * * * \\
(-1.86,-.76)\end{array}$ & $\begin{array}{l}.26^{* * *} \\
(.15, .46)\end{array}$ & $\begin{array}{c}-1.33^{* * *} \\
(-1.88,-.78)\end{array}$ & $\begin{array}{l}.26^{* * *} \\
(.15, .45)\end{array}$ \\
\hline High PAC & & $\begin{array}{c}-3.07 * * * \\
(-3.69,-2.44)\end{array}$ & $\begin{array}{l}.04 * * * \\
(.02, .08)\end{array}$ & $\begin{array}{c}-3.11 * * * \\
(-3.73,-2.49)\end{array}$ & $\begin{array}{l}.04 * * * \\
(.02, .08)\end{array}$ \\
\hline RHD & & $\begin{array}{l}-1.11^{* * *} \\
(-1.54,-.67)\end{array}$ & $\begin{array}{l}.32 * * * \\
(.21, .50)\end{array}$ & $\begin{array}{c}-1.09 * * * \\
(-1.53,-.66)\end{array}$ & $\begin{array}{l}.33 * * * \\
(.21, .51)\end{array}$ \\
\hline $\begin{array}{l}\text { Partial-adherence to } \\
\text { treatment }\end{array}$ & & $\begin{array}{l}-1.65 * * * \\
(-2.35,-.95)\end{array}$ & $\begin{array}{l}.19 * * * \\
(.09, .38)\end{array}$ & $\begin{array}{l}-1.67 * * * \\
(-2.36,-.97)\end{array}$ & $\begin{array}{l}.18^{* * * *} \\
(.09, .37)\end{array}$ \\
\hline $\begin{array}{l}\text { Fully-adherence to } \\
\text { treatment }\end{array}$ & & $\begin{array}{c}-2.85^{* *} \\
(-4.88,-.82)\end{array}$ & $\begin{array}{c}.05^{* *} \\
(.00, .43)\end{array}$ & $\begin{array}{c}-2.84 * * \\
(-4.86,-.83)\end{array}$ & $\begin{array}{c}.05^{* *} \\
(.00, .43)\end{array}$ \\
\hline \multicolumn{6}{|c|}{ Hospital factors (Hospital-level) } \\
\hline $\begin{array}{l}\text { Discharge planning } \\
\text { process } \\
\text { Nurses-patient ratio }\end{array}$ & & & & $\begin{array}{c}-.41 \\
(-1.11, .27) \\
.11^{*} \\
(-.00, .22)\end{array}$ & $\begin{array}{c}.65 \\
(.32,1.32) \\
1.11^{*} \\
(99,1.25)\end{array}$ \\
\hline ICC & $\begin{array}{c}.14 \\
(.06, .30) \\
\end{array}$ & $(.03$ & & & $\begin{array}{l}5 \\
20)\end{array}$ \\
\hline Log likelihood (LL) & -484.47942 & -343 & 183 & & 5196 \\
\hline AIC & 972.9588 & 704 & 366 & & 391 \\
\hline $\mathrm{BIC}$ & 983.2286 & 750 & 506 & & 5229 \\
\hline
\end{tabular}

available to determine the right number of staff nurses or the appropriate ratio required to ensure good quality of care in the inpatient psychiatric unit and ensure patient outcomes. Limited empirical evidence is available to determine the right mix of providers and the best approach to treating patients in the inpatient psychiatric unit.

This study concludes that both patient and hospital factors have a statistically significant influence on the health status among patients with schizophrenia after hospital discharge. Previous studies also indicated that health outcomes could be predicted from both patient factors and a combination of contextual or hospital factors, which could vary considerably [72-74]. However, results may differ by other hospital variables, factors such as unit type (acute care unit or rehabilitation unit), the type of mental health professionals, and by skill mix team. Further research needs to take into account these hospital variables.

\section{Strengths and limitation}

This study provides the first multi-level findings and an evidence base for the health status among patients with schizophrenia, 30 days after hospital discharge in Thailand. The results indicate the best predictive model for health status when combining factors. Many existing multi-level studies in Thailand have shown a greater focus on individual and optimal interventions provided for the patients. However, both patient and hospital factors are crucial in determining health status. These considerations have important implications for mental health policymakers and enable us to obtain clarity through precise information and better allocation of resources. 
There are several limitations to this study. The first limitation is that some of the data was derived from selfreports or subjective, produced by participating patients and caregivers themselves. There is a personal element present here that may lead to bias and an under or overestimation of the health status among the participants. The second limitation is that this study could not identify the exact working nurse-patient ratios because the number of head nurses, nurse supervisors, and deputyhead nurses in the psychiatric unit was included. Finally, providing only the number of nurses may not be enough, and effects may remain unclear about the association between the staff nurse and outcomes due to unit type, staff working experience, type of mental health professionals involved, and skill mix. Thus, future studies are required to improve the overall elements of the findings and establish what might be the optimal level of staffing.

\section{Conclusion}

Our findings provide evidence that some patient and hospital factors influence health status among patients with schizophrenia, 30 days after hospital discharge. This finding indicates the importance of enabling resources to primary caregivers for positive caregiving, continuing care with treatment, an appropriate discharge planning process, and adequate nurse staffing-patient ratio as effective strategies for improving patient health status and post-discharge outcomes.

\section{Supplementary Information}

The online version contains supplementary material available at https://doi. org/10.1186/s12888-020-03001-4.

\section{Additional file 1.}

\section{Abbreviations}

PAC: Positive aspect of caregiving; RHD: Readiness for hospital discharge; PMHS: Professional mental health staffs; MHD: Mental health department

\section{Acknowledgments}

We acknowledge that support to all hospital directors, head nurses, nurse supervisors, and research assistants for their involvement and facilitation at the sites. We are also extremely grateful for and thank all study participants who agreed to participate in our study.

\section{Authors' contributions}

All authors made substantial contributions to the study concept and design and acquisition of data. $\mathrm{AS}^{1}$ did the initial analysis, interpretation of data and drafted the initial manuscript. $\mathrm{AS}^{2}$ was involved in data interpretation and edited the report for submission. MT provided feedback on the initial investigation. $\mathrm{AS}^{2}, \mathrm{RP}, \mathrm{MT}$ were involved in developing and revising the manuscript. All authors read and approved the final manuscript before submission.

\section{Funding}

The authors did not receive any funding for this paper.

\section{Availability of data and materials}

The datasets used and analyzed during the current study are available from the School of Graduate Study, Mahidol University, on reasonable request.

\section{Ethics approval and consent to participate}

Ethics approval was obtained from the Institutional Review Board Faculty of Nursing, Mahidol University (COA No.IRB-NS2018/434.0103), and the ethical review board of the Mental Health Department Institutional Review Board, Thailand (DMH-IRB.COA009/2561). Written informed consent was obtained from all study participants.

\section{Consent for publication}

Not applicable.

\section{Competing interests}

The authors declare that they have no competing interests.

\section{Author details}

${ }^{1}$ D.N.S. Candidate, Faculty of Nursing, Mahidol University, Bangkok, Thailand. ${ }^{2}$ Department of Mental Health and Psychiatric Nursing, Faculty of Nursing, Mahidol University, 999 Phuttamonthon 4 Road, Salaya, Nakhon Pathom 73170, Thailand. ${ }^{3}$ Faculty of Nursing HRH Princess Chulabhorn College of Medical Science, Chulabhorn Royal Academy, Bangkok, Thailand. ${ }^{4}$ Department of Epidemiology, Faculty of Public Health, Mahidol University, Bangkok, Thailand.

Received: 11 May 2020 Accepted: 3 December 2020

Published online: 14 December 2020

\section{References}

1. GBD 2017 Disease and Injury Incidence and Prevalence Collaborators. Global, regional, and national incidence, prevalence, and years lived with disability for 354 diseases and injuries for 195 countries and territories, 1990-2017: a systematic analysis for the global burden of disease study 2017. Lancet. 2018;392(10159):1789-858.

2. Abel KM, Drake R, Goldstein JM. Sex differences in schizophrenia. Int Rev Psychiatry. 2010;22(5):417-28.

3. Charlson FJ, Ferrari AJ, Santomauro DF, Diminic S, Stockings E, Scott JG, et al. Global epidemiology and burden of schizophrenia: findings from the global burden of disease study 2016. Schizophr Bull. 2018;44(6):1195-203.

4. Whiteford HA, Ferrari AJ, Degenhardt L, Feigin V, Vos T. The global burden of mental, neurological and substance use disorders: an analysis from the global burden of disease study 2010. PLoS One. 2015;10(2):1-14.

5. Olsson A-K, Hjärthag F, Helldin L. Predicting real-world functional milestones in schizophrenia. Psychiatry Res. 2016;242:1-6.

6. Ventura J, Subotnik KL, Gitlin MJ, Gretchen-Doorly D, Ered A, Villa KF, et al. Negative symptoms and functioning during the first year after a recent onset of schizophrenia and 8 years later. Schizophr Res. 2015;161(2-3): 407-13.

7. Menendez-Miranda I, Garcia-Portilla MP, Garcia-Alvarez L, Arrojo M, Sanchez P, Sarramea F, et al. Predictive factors of functional capacity and real-world functioning in patients with schizophrenia. Eur Psychiatry. 2015;30(5):622-7.

8. Cardenas V, Abel S, Bowie CR, Tiznado D, Depp CA, Patterson TL, et al. When functional capacity and real-world functioning converge: the role of self-efficacy. Schizophr Bull. 2013;39(4):908-16.

9. Primeau A, Bowers TG, Harrison MA, XuXu. Deinstitutionalization of the mentally ill: evidence for transinstitutionalization from psychiatric hospitals to penal institutions. Compr Psychol. 2013;2(2):361-71.

10. National Institute for Health and Care Excellence Guldeline. Transition between inpatient mental health settings and community or care home settings. NICE copyright material. 2016.

11. Khankeh H, Rahgozar M, Ranjbar M. The effects of nursing discharge plan (post-discharge education and follow-up) on self-care ability in patients with chronic schizophrenia hospitalized in Razi psychiatric center. IJNMR/ Spring. 2010;16(2):162-8.

12. Cheng K-D, Huang C-J, Tsang H-Y, Lin C-H. Factors related to missed first appointments after discharge among patients with schizophrenia in Taiwan. J Formos Med Assoc. 2014;113(7):436-41.

13. Balikci A, Erdem M, Zincir S, Bolu A, Zincir SB, Ercan S, et al. Adherence with outpatient appointments and medication: a two-year prospective study of patients with schizophrenia. Bull Clin Psychopharmacol. 2013;23(1):57-64. 
14. Killaspy H. Psychiatric outpatient services: origins and future. Adv Psychiatr Treat. 2006;12(5):309-19.

15. Eytan A, Gex-Fabry M, Ferrero F, Bertschy G. Missed appointments at outpatient psychiatric clinics in Geneva: a pilot study. Schweiz Arch Neurol Psychiatry. 2004;155:125-8.

16. Killaspy $\mathrm{H}$. Prospective controlled study of psychiatric outpatient nonattendance: characteristics and outcome. Br J Psychiatry. 2000;176(2):160-5.

17. Singla M, Goyal SK, Sood A, Philips A, Philips S. Profile and pattern of followups of psychiatry outpatients at Christian medical college Ludhiana. Ment Health Hum Behav. 2015;20(2):76-9.

18. World Health Organization. Mental health action plan 2013-2020. WHO document production services, Geneva, Switzerland. 2013.

19. World Health Organization. Mental health Atlas 2014. Publications of the World Health Organization 2015.

20. Babitsch B, Gohl D, Lengerke TV. Re-revisiting Andersen's Behavioral Model of Health Services Use: a systematic review of studies from 1998-2011. GMS Psycho-Soc Med. 2012;9:Doc11. https://doi.org/10.3205/psm000089.

21. Mrizak J, Ouanes SAMI, Lakhal M, Rafrafi RYM, El-Hechmi Z. Remission and recovery in schizophrenia: associated socio-demographic and clinical features. Eur Psychiatry. 2014;29(S1):1. https://doi.org/10.1016/S09249338(14)78451-2.

22. Spellmann I, Riedel M, Schennach R, Seemüller F, Obermeier M, Musil R, et al. One-year functional outcomes of naturalistically treated patients with schizophrenia. Psychiatry Res. 2012;198(3):378-85.

23. Hayes RD, Chang C-K, Fernandes AC, Begum A, To D, Broadbent M, et al Functional status and all-cause mortality in serious mental illness. PLoS One. 2012;7(9):1-9.

24. Talreja BT, Shah S, Kataria L. Cognitive function in schizophrenia and its association with socio-demographics factors. Ind Psychiatry J. 2013;22(1): 47-53.

25. Ali A. Disability in schizophrenia and its relationship with duration of illness and age of onset. Int J Psychosoc Rehabil. 2009;14(1):37-41.

26. Schennach-Wolff $R$, Jäger M, Seemüller F, Obermeier M, Messer T, Laux G, et al. Defining and predicting functional outcome in schizophrenia and schizophrenia spectrum disorders. Schizophr Res. 2009;113(2):210-7.

27. Czobor P, Dorn RAV, Citrome L, Kahn RS, Fleischhacker WW, Volavka J. Treatment adherence in schizophrenia: A patient-level meta-analysis of combined CATIE and EUFEST studies. Eur Neuropsychopharmacol. 2015;25: $1158-66$.

28. Novick D, Haro JM, Suarez D, Perez V, Dittmann RW, Haddad PM. Predictors and clinical consequences of non-adherence with antipsychotic medication in the outpatient treatment of schizophrenia. Psychiatry Res. 2010;176:109-13.

29. Higashi K, Medic G, Littlewood K, Diez T, Granström O, De Hert M. Medication adherence in schizophrenia: factors influencing adherence and consequences of nonadherence, a systematic literature review. Ther Adv Psychopharmacol. 2013:3(4):200-18.

30. Kassis IT, Ghuloum S, Mousa H, Bener A. Treatment non-compliance of psychiatric patients and associated factors: are patients satisfied from their psychiatrist? Br J Med Med Rese. 2014;4(2):785-96.

31. Hilgeman MM, Allen RS, Decoster J, Burgio LD. Positive aspects of caregiving as a moderator of treatment outcome over 12 months. Psychol Aging. 2007;22(2):361-71

32. Glick ID, Stekoll AH, Hays S. The role of the family and improvement in treatment maintenance, adherence, and outcome for schizophrenia. J Clin Psychopharmacol. 2011;31(1):82-5.

33. lasevoli F, Giordano S, Balletta R, Latte G, Formato MV, Prinzivalli E, et al. Treatment resistant schizophrenia is associated with the worst community functioning among severely-ill highly-disabling psychiatric conditions and is the most relevant predictor of poorer achievements in functional milestones. Prog Neuro-Psychopharmacol Biol Psychiatry. 2016;65:34-48.

34. Adelufosi A, Ogunwale A, Adeponle A, Abayomi O. Pattern of attendance and predictors of default among Nigeria outpatients with schizophrenia. Afr J Psychiatry. 2013;16:283-7.

35. Andersen RM, Davidson PL. Improving access to care in America: individual and contextual indicators: Changing the US health care system: key issues in health services policy and management. San Francisco: Jossey-Bass; 2007. p. 3-31.

36. Lin H-C, Lee H-C. Psychiatrists' caseload volume, length of stay and mental healthcare readmission rates: a three-year population-based study. Psychiatry Res. 2009;166(1):15-23.
37. Han K-T, Lee SY, Kim SJ, Hahm M-I, Jang S-I, Kim SJ, et al. Readmission rates of south Korean psychiatric inpatients by inpatient volumes per psychiatrist. BMC Psychiatry. 2016;16(69):1-10.

38. Tharani A, Farooq S, Naveed A. Community mental health services: a way forward to rehabilitate chronic mentally ill client. J Ayub Med Coll Abbottabad. 2012;24(2):140-3.

39. WHO and Ministry of Public Health. WHO-AIMS Report on Mental Health System in Thailand. Nonthaburi, Bangkok, Thailand: WHO and Ministry of Public Health; 2006.

40. Pavasuthipaisit C, Chotpitayasunondh V, Ussanarassamee A. ASEAN Mental Health Systems. Thailand: Jakarta, ASEAN Secretariat; 2016.

41. Department of Mental Health. Anual Report 2015. Department of Mental Health, ministry of public health, Thailand. 2015.

42. Krejcie RV, Morgan DW. Determining sample size for research activities. Educ Psychol Meas. 1970;30:607-10.

43. Phuaphanprasert B, Srisurapanont M, Silpakit C, Pannarunothai S, Udomratn P, Geater A, et al. Reliability and validity of the Thai version of the health of the nation outcome scales (HoNOS). Med Assoc Thai. 2007;90(11):2487-93.

44. Parabiaghi A, Barbato A, D'Avanzo B, Erlicher A, Lora A. Assessing reliable and clinically significant change on health of the nation outcome scales: method for displaying longitudinal data. Aust N Z J Psychiatry. 2005:39:719-25.

45. Weiss M, Piacentine L. Psychometric properties of the readiness for hospital discharge scale. J Nurs Meas. 2006;14(3):163-80.

46. Sriprasong S, Hanucharurnkul S, Panpukdee O, Krittayaphong R, Pongthavornkamol K, Vorapongsathorn T. Personal factors related to perceived readiness for hospital discharge of patients with acute myocardia infarction. Thai J Cardiothorac Nurs. 2011;22(2):44-57.

47. Tarlow BJ, Wisniewski SR, Belle SH, Rubert M, Ory MG. Dolores Gallagher-Tho p. positive aspects of caregiving. Res Aging. 2004;26(4):429-53.

48. Department of Mental Health, Ministry of Public Health, Thailand. Annual Report 2018.

49. Gonçalves-Bradley DC, Lannin NA, Clemson LM, Cameron ID, Shepperd S. Discharge planning from hospital. Cochrane Database Syst Rev. 2016;(1):1103.

50. Austin PC, Merlo J. Intermediate and advanced topics in multi-level logistic regression analysis. Stat Med. 2017;36:3257-77.

51. Penno SJ, Hamilton B, Petrakis M. Early intervention in psychosis: health of the nation outcome scales (HoNOS) outcomes from a five-year prospective study. Arch Psychiatr Nurs. 2017;31(6):553-60.

52. Cotton SM, Lambert M, Schimmelmann BG, Filia KM, Rayner $V$, Hides L, et al. Predictors of functional status at service entry and discharge among young people with first episode psychosis. Soc Psychiatry Psychiatr Epidemiol. 2017:5:575-85.

53. Luo W, Harvey R, Tran T, Phung D, Venkatesh S, Connor JP. Consistency of the health of the nation outcome scales (HoNOS) at inpatient-tocommunity transition. BMJ. 2016;6(4):1-9.

54. Valencia M, Fresán A, Barak Y, Juárez F, Escamilla R, Saracco R. Predicting functional remission in patients with schizophrenia: a cross-sectional study of symptomatic remission, psychosocial remission, functioning, and clinical outcome. Neuropsychiatr Dis Treat. 2015;11:2339-48.

55. Kelly DL, Rowland LM, Patchan KM, Sullivan K, Earl A, Raley H, et al. Schizophrenia clinical symptom differences in women vs. men with and without a history of childhood physical abuse. Child Adolesc Psychiatry Ment Health. 2016;10(5):1-7.

56. Grossman LS, Harrow M, Rosen C, Faull R, Strauss GP. Sex differences in schizophrenia and other psychotic disorders: a 20-year longitudinal study of psychosis and recovery. Compr Psychiatry. 2008;49(6):523-9.

57. Carpiniello B, Pinna F, Tusconi M, Zaccheddu E, Fatteri F. Gender differences in remission and recovery of schizophrenic and schizoaffective patients: preliminary results of a prospective cohort study. Schizophr Res Treat. 2012; 2012:50-7.

58. Svettini A, Johnson B, Magro C, Saunders J, Jones K, Silk S, et al. Schizophrenia through the carers' eyes: results of a European cross-sectional survey. J Psychiatr Ment Health Nurs. 2015;22(7):472-83.

59. GLdP Z, Moro LM, Ferreira GS, KtB R. Factors associated with psychiatric readmissions: a systematic review. Psychol Health. 2018;28(2814):1-10.

60. Meng N, Liu R, Wang M, Liao J, Feng C, Li X. The association between patient-reported readiness for hospital discharge and outcomes in patients diagnosed with anxiety disorders: a prospective and observational study. J Psychiatr Ment Health Nurs. 2020;27(4):380-92. 
61. Schmocker RK, Holden SE, Vang X, Leverson GE, Stafford LMC, Winslow ER. Association of Patient-Reported Readiness for discharge and hospital consumer assessment of health care providers and systems patient satisfaction scores: a retrospective analysis. J Am Coll Surg. 2015;221(6): 1073-82.

62. Celia LM. Discharge readiness in heart failure. A Thesis Submitted to the Faculty of Drexel University in partial fulfillment of the requirements for the degree of Doctor of Nursing Practice. 2015.

63. Sendt K-V, Tracy DK, Bhattacharyya S. A systematic review of factors influencing adherence to antipsychoticmedication in schizophreniaspectrum disorders. Psychiatry Res. 2015;225:14-30.

64. Alpak G, Aksoy I, Demir B, Unal A, Virit O, Bulbul F, et al. Missed Appointments and Medication Non-compliance Among Consecutive Psychiatric Patients. J Mood Disord. 2015;5(4):151-6.

65. Lee Y, Lee M-S, Jeong H-G, Youn H-C, Kim S-H. Medication adherence using electronic monitoring in severe psychiatric illness: 4 and 24 weeks after discharge. Clin Psychopharmacol Neurosci. 2019;17(2):288-96.

66. Mekuriaw B, Abera M, Tessema W, Agenagnew L, Dawud B, Abdisa E, et al. Medication non-adherence and use of traditional treatment among adult psychiatric patients in Jimma town treated at Jimma University teaching hospital psychiatric clinic. Community based cross-sectional study, 2016. J Psychiatry. 2018;21(1):1-7.

67. Siddiqui MA, Pattojoshi A, Khess CRJ. Factors affecting adherence in patients with schizophrenia. Int J Adv Med. 2016;3(1):25-32.

68. Bridges J. Griffiths P, Oliver E, Pickering RM. hospital nurse staffing and staffpatient interactions: an observational study. BMJ Qual Saf. 2019;28:706-13.

69. Okumura Y, Sugiyama N, Noda T, Sakata N. Association of high psychiatrist staffing with prolonged hospitalization, follow-up visits, and readmission in acute psychiatric units: a retrospective cohort study using a nationwide claims database. Neuropsychiatr Dis Treat. 2018;14:893-902.

70. Aiken LH, Clarke SP, Sloane DM, Sochalski J, Silber JH. Hospital nurse staffing and patient mortality, nurse burnout, and job dissatisfaction. JAMA. 2002; 288(16):1987-93.

71. Zhu X-w, L-m Y, Zheng J, Liu K, J-b F, S-x H, et al. Nurse staffing levels make a difference on patient outcomes: a multisite study in Chinese hospitals. J Nurs Scholarsh. 2012;44(3):266-73.

72. Thornton K. Associations between multi-level contextual factors and mental health service utilization in adolescents with comorbid depression and substance-use: moderating role of school connectedness on racial/ethnic disparities in service utilization. A Thesis Submitted to the Graduate Faculty of Georgia State University in Partial Fulfillment of the requirements for the Master Degree of Public Health, Georgia State University. 2017.

73. Chung W, Chang H-S, Oh S-M, Yoon C-W. Factors associated with long-stay status in patients with schizophrenia: an analysis of national databases covering the entire Korean population. Int J Soc Psychiatry. 2013;59(3): 207-16.

74. Ngui AN, Perreault M, Fleury MJ, Caron J. A multi-level study of the determinants of mental health service utilization. EpidemiolPublic Health. 2012;60:85-93.

\section{Publisher's Note}

Springer Nature remains neutral with regard to jurisdictional claims in published maps and institutional affiliations.

Ready to submit your research? Choose BMC and benefit from:

- fast, convenient online submission

- thorough peer review by experienced researchers in your field

- rapid publication on acceptance

- support for research data, including large and complex data types

- gold Open Access which fosters wider collaboration and increased citations

- maximum visibility for your research: over $100 \mathrm{M}$ website views per year

At BMC, research is always in progress.

Learn more biomedcentral.com/submissions 